\section{Powdery Mildew Resistance in the Peach Cultivar Pamirskij 5 Is Genetically Linked with the $G r$ Gene for Leaf Color}

\author{
Thierry Pascal ${ }^{1}$, Fred Pfeiffer, and Jocelyne Kervella \\ Institut National de la Recherche Agronomique (INRA), UR 1052, GAFL- \\ Unité de Génétique et Amélioration des Fruits et Légumes BP 94-84143 \\ MONTFAVET Cedex, France
}

Additional index words. Prunus persica, genetic determinism, linkage

\begin{abstract}
Peach powdery mildew (Podosphaera pannosa var. persicae) is a major disease of peach trees [Prunus persica (L.) Batsch]. Various studies on powdery mildew resistance have been conducted in peach. The present study was initiated to determine the inheritance of powdery mildew resistance found in the green leaf peach rootstock 'Pamirskij 5'. Crosses were carried out between 'Pamirskij 5' and the susceptible red leaf peach rootstock 'Rubira' ${ }^{\circledR}$. Segregation analysis performed in $F_{1}(1: 0), F_{2}(3: 1)$, and test cross $(1: 1)$ progenies indicated single dominant gene control of peach powdery mildew resistance in 'Pamirskij 5'. Cosegregation analysis provided clear evidence that the loci for powdery mildew resistance and the leaf color trait are very closely linked in 'Pamirskij 5'. The estimated distance between these loci was $0 \pm 3.26 \mathrm{cM}$ for the $\mathrm{F}_{2}$ and $0 \pm 0.00 \mathrm{cM}$ for the test cross populations.
\end{abstract}

Peach powdery mildew caused by Podosphaera pannosa (Wallr.) var. persicae is a fungal disease of the cultivated peach (Prunus persica L. Batsch) spread throughout all European production areas. Circular whitish spots on leaves, young twigs, and fruits are typical symptoms of powdery mildew infection. The disease may induce necrosis and deformations resulting in unmarketable fruit, premature leaf drop, and shoot stunting harmful to the crop. Most peach cultivars are susceptible to powdery mildew and numerous applications of fungicide are required from prebloom until after harvest. To satisfy consumers' request for a reduction of chemical inputs (Byrne, 2002) and for an environmentally safe solution, resistant cultivars are a desirable alternative to fungicides for effective control of powdery mildew.

Various studies have been conducted to evaluate peach cultivars and Prunus species for their response to powdery mildew. Several sources of resistance have been identified in related wild species close to P. persica (Smykov et al., 1982). The polygenic resistance of $P$. davidiana (Carr.) Franch. is already being exploited in a breeding program (Foulongne et al., 2003a, 2003b). The Ee locus controlling the presence/absence and shape of foliar glands in peach has been reported to be associated with very high susceptibility to this fungus (Watkin and Brown, 1956). This has led peach breeders to select only glandular cultivars. Among glandular cultivars, a single

Received for publication 3 Aug. 2009. Accepted for publication 22 Oct. 2009.

${ }^{1}$ To whom reprint requests should be addressed; e-mail tpascal@avignon.inra.fr. dominant gene conferring resistance to powdery mildew was found in 'Ustoichivy Pozdni' (Tsukanova et al., 1982). Powdery mildew resistance in $P$. ferganensis (Kost. and Rjab) Kov. and Kost. (Dabov, 1983) was found to involve two loci: the partially dominant allele $V r$ controls high resistance and is epistatic to the dominant allele $\mathrm{Sr}$ controlling low resistance.

In France, seeds of a new resistance source called 'Pamirskij 5' (clone S 6146) ical Garden of Yalta (Crimea, Ukraine) through the courtesy of Professor Eremin States (personal communication) that the powdery mildew resistance of 'Pamirskij 5' was higher than resistant cultivars such as Malo Konare developed by Dabov (1985). In our environmental conditions, 'Pamirskij 5' has shown a high level of resistance to powdery mildew in different experiments over several years. The main objective of this study was to determine the genetic control of resistance to powdery mildew in the peach rootstock cultivar Pamirskij 5. The second was to assess linkage relationships between resistance to powdery mildew and two major genes brought by the peach rootstock cultivar Rubira ${ }^{\circledR}$ (clone S2605), used here as the powdery mildew-susceptible parent and homozygous, respectively, for the resistance to the green peach aphid Myzus persicae (Pascal et al., 2002) and the red leaf character (Grgr).

\section{Materials and Methods}

Two hundred fifty $F_{1}$ hybrids were obtained from a first cross between 'Rubira' ${ }^{\circledR}$ and 'Pamirskij 5'. $F_{2}$ families were produced have been introduced from the Nikita Botan- by self-pollination of five $\mathrm{F}_{1}$ hybrid plants and a pseudo-test cross $\left(\mathrm{TC}_{1}\right)$ population was generated by crossing one $\mathrm{F}_{1}$ hybrid with 'Big Top' ${ }^{\circledR}$ (clone 5811), a nectarine cultivar susceptible to powdery mildew with green foliage. Selfed progenies $\left(\mathrm{S}_{1}\right)$ of the parental cultivars were created at each step of the genetic study. Seeds from all crosses were harvested at full maturity, extracted, and stratified. After radicle emergence, seeds were planted individually in 1-L plastic pots containing a commercial horticultural mix and randomized in a greenhouse. Temperatures were maintained at $23 \pm 5{ }^{\circ} \mathrm{C}$ and seedlings were watered daily ad libitum with a commercial solution containing micronutrients.

Plants were evaluated for resistance to the green peach aphid (Pascal et al., 2002), scored for red or green leaf color, and pruned before artificial inoculation by $S$. pannosa once they developed succulent shoots. Initially, the inoculum source derived from the populations endemic to Avignon (France) was maintained on potted susceptible peach seedlings. Inoculations were carried out by blowing or shaking fungal spores from these heavily infected plants onto young test progenies. In addition, heavily infected susceptible plants were grown adjacent to the progenies being tested as a continuing source of inoculum. Plants were evaluated three times over a 4 -week period using a well-tried linear rating scale consisting of the following: $0=$ no visible symptoms to $4=$ white spots completely covering leaves and young stems (Dirlewanger et al., 1996; Foulongne et al., 2003a, 2003b; Pascal et al., 1998). Plants scored 0 and 1 were considered resistant. Segregation ratios were analyzed using standard $\chi^{2}$ procedures. Maximum likelihood tables (Allard, 1956) were used to calculate recombination rates for close linkages. The recombination rates were converted to map distances in centiMorgans (cM) using the formula of Kosambi (1944).

\section{Results and Discussion}

All $S_{1}$ progenies of 'Rubira' ${ }^{\circledR}$ were uniformly and highly susceptible to infection by powdery mildew in both experiments. Conversely, all $\mathrm{S}_{1}$ progenies of 'Pamirskij 5' as well as all $F_{1}$ plants were uniformly and highly resistant (Table 1). These results show that 'Pamirskij 5' and 'Rubira' ${ }^{\circledR}$ are homozygous for resistance and susceptibility to powdery mildew, respectively. The high level of resistance expressed by all $\mathrm{F}_{1}$ plants indicates that resistance is dominant to susceptibility. Segregation data from the $\mathrm{F}_{2}$ and $\mathrm{TC}_{1}$ progenies were tested for goodness-of-fit to expected ratios using $\chi^{2}$ analysis. The results of the $\chi^{2}$ analysis indicate that the $\mathrm{F}_{2}$ and $\mathrm{TC}_{1}$ progenies fit $3: 1$ and 1:1 ratios, respectively. The data are consistent with powdery mildew resistance in 'Pamirskij 5' being controlled by a single homozygous dominant gene that we propose to call $V r 2$.

The use of single dominant genes for the development of resistant cultivars is highly controversial because of resistance durability aspects. However, in a perennial plant such 
as peach, little effort has been devoted to pest improvement and few sources of resistance are available. The use at short term by peach breeders of $V r 2$ could constitute an essential first step to the development of more stable and long-lasting resistance. Furthermore, this use would be fully justified by the high level of resistance to powdery mildew of 'Pamirskij 5', which is clearly more resistant than most current conventional peach cultivars Dabov (Arregui et al., 1999). Nevertheless, to better characterize the resistance genes originating from different genetic backgrounds, it would be necessary to test for allelism the resistance originating from 'Pamirskij 5' and 'Malo Konare'.

Two linkage tests were conducted involving powdery mildew resistance from 'Pamirskij 5 ' and green peach aphid resistance and the red leaf traits from 'Rubira' ${ }^{\circledR} \cdot \chi^{2}$ analysis of segregation data were consistent with independent assortment of powdery mildew resistance and green peach aphid resistance (data not shown). Conversely, distorted segregation ratios were observed in the joint distributions of powdery mildew resistance and the leaf color character (Table 2). In $\mathrm{F}_{2}$ populations, there was an excess of parental types (susceptible red and resistant green) and than resistant cultivars developed by

and a large shortage of recombinant types (resistant red and susceptible green). Recombinants with susceptibility to powdery mildew and green foliage phenotype were not observed in $\approx 940 \mathrm{~F}_{2}$ plants. Similarly, no recombinant types were observed in the $\mathrm{TC}_{1}$ population. From these results we could postulate that the resistant red leaf progeny were heterozygous at both loci $(\mathrm{Vr} 2 \mathrm{vr} 2 \mathrm{Grgr})$ analogous to the $F_{1}$ hybrids. These results clearly indicate a very strong linkage in the repulsion phase $\left(\chi^{2}=105.3, P=0\right)$ between the $V r 2$ resistant allele and the red leaf color allele in 'Rubira' ${ }^{\circledR}$, which constitutes a new case of linkage in peach.

On the basis of pooled $\mathrm{F}_{2}$ and $\mathrm{TC}_{1}$ data (Table 2), the recombination rate between these two genes was calculated as equal to $3.26 \%$ and $0 \%$, respectively. The genetic distance converted from the $\mathrm{F}_{2}$ recombination rate was $0 \pm 3.26 \mathrm{cM}$. Based on $\mathrm{TC}_{1}$ data, the recombination rate was equal to $0 \pm 0.00 \mathrm{cM}$.

The linkage between $G r$ and $V r 2$ could be used for marker-assisted selection in the introduction of the 'Pamirskij 5 ' resistance gene to peach powdery mildew in fruit cultivars. The $G r$ gene controlling red leaf color has been mapped to linkage group 6 both in a genetic map derived from an interspecific cross with GN22 (Dirlewanger et al., 2004)

Table 1. Segregation ratios for reaction to peach powdery mildew and leaf color of parental selfs, $F_{1}, F_{2}$, and test cross progenies derived from the resistant peach cultivar Pamirskij 5 and the susceptible peach cultivar with red foliage, 'Rubira'.

\begin{tabular}{|c|c|c|c|c|c|}
\hline \multirow[b]{2}{*}{ Cross } & \multicolumn{2}{|c|}{ Progeny observed } & \multirow{2}{*}{$\begin{array}{l}\text { Expected } \\
\text { ratios }^{z}\end{array}$} & \multirow[b]{2}{*}{$\chi^{2}(1 \mathrm{df})$} & \multirow[b]{2}{*}{$P$} \\
\hline & Resistant & Susceptible & & & \\
\hline$\overline{(\text { Rubira })^{2} \mathrm{~S} 1}$ & 0 & 45 & $0: 1$ & - & - \\
\hline$(\text { Pamirskij 5) })^{2} \mathrm{~S} 1$ & 131 & 0 & 1: 0 & - & - \\
\hline Rubira $\times$ Pamirskij 5 F1 & 250 & 0 & 1: 0 & - & - \\
\hline$\left[(\text { Rubira } \times \text { Pamirskij 5)1 }]^{2}\right.$ F2 & 210 & 67 & 3: 1 & 0.097 & 0.754 \\
\hline$\left[(\text { Rubira } \times \text { Pamirskij 5)2 }]^{2}\right.$ F2 & 53 & 19 & 3: 1 & 0.074 & 0.785 \\
\hline$\left[(\text { Rubira } \times \text { Pamirskij 5)3 }]^{2}\right.$ F2 & 197 & 63 & 3: 1 & 0.082 & 0.774 \\
\hline$\left[(\text { Rubira } \times \text { Pamirskij 5)4 }]^{2}\right.$ F2 & 217 & 63 & 3: 1 & 0.933 & 0.333 \\
\hline$\left[(\text { Rubira } \times \text { Pamirskij 5)5 }]^{2}\right.$ F2 & 37 & 14 & 3: 1 & 0.163 & 0.686 \\
\hline \multirow{2}{*}{$\begin{array}{l}{[(\text { Rubira } \times \text { Pamirskij 5) } 1] \times \text { Big }} \\
\quad \text { Top TC1 }\end{array}$} & 257 & 264 & $1: 1$ & 0.094 & 0.759 \\
\hline & Red & Green & & & \\
\hline$(\text { Rubira })^{2} \mathrm{~S} 1$ & 45 & 0 & 1: 0 & - & - \\
\hline$(\text { Pamirskij 5) })^{2} \mathrm{~S} 1$ & 0 & 131 & $0: 1$ & - & - \\
\hline Rubira $\times$ Pamirskij 5 F1 & 250 & 0 & 1: 0 & - & - \\
\hline F2 pooled data for leaf color & 696 & 244 & 3: 1 & 0.459 & 0.497 \\
\hline
\end{tabular}

${ }^{\mathrm{z}}$ Expected segregation based on a one-gene model with powdery mildew resistance and red leaf trait dominant.

Table 2. Evidence for repulsion phase linkage between the genes for resistance to peach powdery mildew and leaf color in peach.

\begin{tabular}{|c|c|c|c|c|c|c|c|c|}
\hline \multirow[b]{3}{*}{ Cross } & \multicolumn{4}{|c|}{ Progeny observed } & \multirow{3}{*}{$\begin{array}{c}\text { Expected } \\
\text { ratios }^{z}\end{array}$} & \multirow[b]{3}{*}{$\chi^{2}$} & \multirow[b]{3}{*}{$\mathrm{df}$} & \multirow[b]{3}{*}{$P$} \\
\hline & \multicolumn{2}{|c|}{ Resistant } & \multicolumn{2}{|c|}{ Susceptible } & & & & \\
\hline & $\overline{\operatorname{Red}}$ & Green & Red & $\overline{\text { Green }}$ & & & & \\
\hline$\overline{\left[(\text { Rubira } \times \text { Pamirskij 5)1 }]^{2} \text { F2 }\right.}$ & 135 & 75 & 67 & 0 & $9: 3: 3: 1$ & 34.7 & 3 & $3.10^{-9}$ \\
\hline$\left[(\text { Rubira } \times \text { Pamirskij 5)2 }]^{2}\right.$ F2 & 28 & 25 & 19 & 0 & $9: 3: 3: 1$ & 20.3 & 3 & $6.10^{-6}$ \\
\hline$\left[(\text { Rubira } \times \text { Pamirskij 5) } 3]^{2}\right.$ F2 & 129 & 68 & 63 & 0 & $9: 3: 3: 1$ & 30.1 & 3 & $4.10^{-8}$ \\
\hline$\left[(\text { Rubira } \times \text { Pamirskij 5)4] }]^{2}\right.$ F2 & 154 & 63 & 63 & 0 & $9: 3: 3: 1$ & 21.7 & 3 & $3.10^{-6}$ \\
\hline$\left[(\text { Rubira } \times \text { Pamirskij 5)5 }]^{2}\right.$ F2 & 24 & 13 & 14 & 0 & $9: 3: 3: 1$ & 7.2 & 3 & 0.007 \\
\hline F2 pooled data & 470 & 244 & 226 & 0 & $9: 3: 3: 1$ & 105.3 & 3 & 0 \\
\hline F2 homogeneity & & & & & & 12.7 & 8 & 0.11 \\
\hline$[($ Rubira $\times$ Pamirskij 5) 1$] \times$ Big & 0 & 257 & 264 & 0 & $1: 1: 1: 1$ & 521.1 & 3 & 0 \\
\hline
\end{tabular}

Top TC1

${ }^{\mathrm{z} E x p e c t e d ~ s e g r e g a t i o n ~ b a s e d ~ o n ~ a ~ t w o ~ i n d e p e n d e n t ~ g e n e ~ m o d e l ~ w i t h ~ p o w d e r y ~ m i l d e w ~ r e s i s t a n c e ~ a n d ~ r e d ~}$ leaf trait dominant. and another from an intraspecific cross between Japanese peach cultivars Akame and Juseitou (Yamamoto et al., 2005). This would suggest starting the search for linked molecular markers on linkage group 6 and would be consistent with the fact that in $P$. davidiana, the quantitative trait locus (QTL) with the strongest effect for powdery mildew resistance, was on this linkage group (Foulongne et al., 2003a, 2003b). Vr2 would thus be located on a linkage group distinct from the major quantitative trait locus (QTL) of resistance to peach powdery mildew from $P$. ferganensis, which mapped on linkage group 7 (Dettori et al., 2001; Verde et al., 2002) and is associated with the Ee foliar gland locus. The diversity of genomic loci implicated in powdery mildew resistance in peach and related species should make possible the pyramiding of different resistant genes to build more durable resistance.

\section{Literature Cited}

Allard, R.W. 1956. Formulas and tables to facilitate the calculation of recombination values in heredity. Hilgardia 24:235-278.

Arregui, M., T. Pascal, F. Pfeiffer, M. Foulongne, and J. Kervella. 1999. Evaluation of peach and wild species genotypes for resistance to Sphaerotheca pannosa. Proc. of the First International Powdery Mildew Conference held at Avignon, France, 29 Aug. to 2 Sept. p. 73.

Byrne, D.H. 2002. Peach breeding trends: A world wide perspective. Acta Hort. 592:49-59.

Dabov, S. 1983. Inheritance of powdery mildew resistance in the peach. IV. Data supporting the hypothesis about the main role of 2 loci controlling the reaction to the pathogen. Genet. Sel. 16:349-355.

Dabov, S. 1985. 'Malo Konare'-A new canning peach variety. Rast. Nauki 22:84-87.

Dettori, M.T., R. Quarta, and I. Verde. 2001. A peach linkage map integrating RFLPs, SSRs, RAPDs, and morphological markers. Genome 44:783-790.

Dirlewanger, E., P. Cosson, W. Howad, G. Capdeville, N. Bosselut, M. Claverie, R. Voisin, C. Poizat, B. Lafargue, O. Baron, F. Laigret, M. Kleinhentz, P. Arús, and D. Esmenjaud. 2004. Microsatellite genetic linkage maps of myrobalan plum and an almond-peach hybrid-location of root-knot nematode resistance genes. Theor. Appl. Genet. 109: $827-838$.

Dirlewanger, E., T. Pascal, C. Zuger, and J. Kervella. 1996. Analysis of molecular markers associated with powdery mildew resistance genes in peach [Prunus persica (L.) Batsch] $\times$ Prunus davidiana hybrids. Theor. Appl. Genet. 93:909-919.

Foulongne, M., T. Pascal, F. Pfeiffer, and J. Kervella. 2003a. QTLs for powdery mildew resistance in peach $\times$ Prunus davidiana crosses: Consistency across generations and environments. Mol. Breed. 12:33-50.

Foulongne, M., T. Pascal, P. Arús, and J. Kervella. 2003b. The potential of Prunus davidiana for introgression into peach [Prunus persica (L.) Batsch] assessed by comparative mapping. Theor. Appl. Genet. 107:227-238.

Kosambi, D.D. 1944. The estimation of map distances from recombination values. Ann. Eugen. 12:172-175.

Pascal, T., J. Kervella, F. Pfeiffer, J.P. Lacroze, and M.H. Sauge. 2002. Inheritance of the green peach aphid resistance in the peach cultivar 'Rubira ${ }^{\circledR}$. Plant Breed. 121:459-461. 
Pascal, T., J. Kervella, F. Pfeiffer, M.H. Sauge, and D. Esmenjaud. 1998. Evaluation of the interspecific progeny Prunus persica cv. Summergrand $\times$ Prunus davidiana for disease resistance and some agronomic features. Acta Hort. 465:185-192.

Smykov, V.K., G.V. Ovcharenko, Z.N. Perfilyeva, and E.P. Shoeferistov. 1982. Estimation of the peach hybrid resources by its mildew resistance against the infection background [in Russian]. Bull. Gos. Nik. Bot. Sada 88:74-80.

Tsukanova, Z.G., S.A. Sokolova, E.S. Gatina, and V.K. Smykov. 1982. Inheritance of mildew resistance by peaches [in Russian]. Bull. Gos. Nik. Bot. Sada 49:72-75.

Verde, I., R. Quarta, C. Cedrola, and M.T. Dettori. 2002. QTL analysis of agronomic traits in a BC1 peach population. Acta Hort. 592:291-297.
Watkin, W. and A.G. Brown. 1956. Genetic response to selection in cultivated plants: Gene frequencies in varieties of Prunus persica. Proc. R. Soc. Lond. B. Biol. Sci. 145:337347.

Yamamoto, T., M. Yamaguchi, and T. Hayashi. 2005. An integrated genetic linkage map of peach by SSR, STP, AFLP and RAPD. J. Jpn. Soc. Hort. Sci. 74:204-213. 